\title{
Nationwide Survey of Neurologic Manifestations of Acquired Immunodeficiency Syndrome in Japan
}

\author{
Masanori Nakagawa, Yoshikazu Maruyama, Hideo Sugita* and Mitsuhiro Osame
}

To study the epidemiology of the neurologic manifestations of human immunodeficiency virus (HIV)-1 infection in Japan, we conducted two nationwide surveys. Of 1854 HIV-1 carriers, 578 had acquired immunodeficiency syndrome (AIDS) and 166 (28.7\% of AIDS patients) had neurologic manifestations including HIV dementia (11.8\%), myelopathy $(3.6 \%)$ and peripheral neuropathy $\mathbf{( 2 . 6 \% )}$. The incidence of neurologic manifestations in patients with HIV-1 infection through blood products was about $60 \%$ of that in patients with HIV-1 infection through sex or unknown routes. This nationwide survey showed that the incidence of neurologic manifestations in AIDS patients in Japan was consistent with that in other countries.

(Internal Medicine 36: 175-178, 1997)

Key words: acquired immunodeficiency syndrome (AIDS), dementia, myelopathy, human immunodeficiency virus (HIV)-1, epidemiology

\section{Introduction}

Human immunodeficiency virus type 1 (HIV-1) infection has gradually become endemic in Japan since 1985 (1). In April 1996, the Acquired Immunodeficiency Syndrome (AIDS) Surveillance Committee of the Ministry of Health and Welfare of Japan reported that cumulative numbers of HIV-1 carriers, patients with AIDS and deceased AIDS patients in Japan were 3642,1140 and 749, respectively. Opportunistic infections and neurologic manifestations are common complications in HIV1 infection. Epidemiological studies revealed that neurologic manifestations such as HIV dementia, vascular myelopathy and neuropathy were present in $26 \%$ to $50 \%$ of patients with HIV1 infection $(2,3)$. Of the neurologic manifestations, HIV dementia was observed in $7.3 \%$ to $15 \%$ of patients with AIDS (3-8). Case reports of neurologic manifestations caused by HIV-1 infection have increased in Japan with increasing numbers of HIV-1 carriers and AIDS patients (9-15). However, no nationwide surveys focusing on the neurologic manifestations of HIV-1 infection have been conducted in Japan. We performed a nationwide survey of the neurologic manifestations of HIV-1 infection in Japan, and found that about $30 \%$ of Japanese AIDS patients have neurologic manifestations.

For editorial comment, see p 160.

\section{Methods}

Two nationwide surveys were conducted. In the first stage of the survey from January to March 1994, we mailed survey forms to 1,675 institutions including all university and national hospitals throughout Japan. The survey forms requested information on the number of HIV-1 carriers, patients with AIDS, patients with neurologic manifestations suspected to be caused by HIV-1 infection and types of the neurologic manifestations.

In the second stage of the survey in April 1995, we mailed a more detailed survey form to 72 institutions that had reported patients with neurologic manifestations caused by HIV-1 infection. The second survey form requested the following information regarding each patient with neurologic manifestations; birth date, sex, age, age at time of HIV-1 infection, age at onset of AIDS, route of HIV-1 infection, neurological findings, blood cell counts, $\mathrm{CD} 4, \mathrm{CD} 8$, brain computed tomography (CT) and magnetic resonance imaging (MRI) findings, cerebrospinal fluid examination, and peripheral nerve conduction study. In addition to this detailed information of the patients, we requested cumulative numbers of HIV-1 carriers, patients with AIDS, patients with neurologic manifestations caused by HIV1 infection and types of the neurologic manifestations classified according to route of HIV-1 infection.

Diagnosis of AIDS and HIV-1-associated neurologic mani-

From the Third Department of Internal Medicine, Kagoshima University School of Medicine, Kagoshima and *National Center of Neurology and Psychiatry, Tokyo 187

Received for publication July 29, 1996; Accepted for publication December 9, 1996

Reprint requests should be addressed to Dr. Masanori Nakagawa, the Third Department of Internal Medicine, Kagoshima University School of Medicine, 8-351 Sakuragaoka, Kagoshima 890 
festations was made based on the 1993 revised center for disease control (CDC) classification system for HIV infection and expanded surveillance case definition for AIDS (16) and the Ministry of Health and Welfare of Japan surveillance case definition for AIDS (17).

\section{Results}

In the first nationwide survey, 1,675 institutions were contacted and 1,075 (64.2\%) replied (Table 1). Of the 1,854 individuals with HIV-1 infection, 578 were diagnosed as having AIDS. Of these patients, 166 patients (28.7\% of 578 AIDS patients on assumption that the neurologic manifestations were associated with AIDS) had neurologic manifestations caused by HIV-1 infection, including 68 patients $(11.8 \%)$ with HIV dementia, 21 patients with myelopathy (3.6\%), 15 patients with peripheral neuropathy (2.6\%), 12 patients with toxoplasmosis of the brain $(2.1 \%)$, and 9 patients with progressive multifocal leukoencephalopathy (1.6\%) (Table 2).

In the second nationwide survey, the 72 institutions that had reported patients with neurologic manifestations were contacted and $34(47.2 \%)$ responded. Of the total of 333 individuals with HIV-1 infection reported by these 34 institutions, 164 were diagnosed as having AIDS. Of the 164 AIDS patients, 107 patients $(65.2 \%$ of 164 AIDS patients on assumption that these neurologic manifestations were associated with AIDS) had neurologic manifestations. Of 188 patients with hemophilia and HIV-1 infection, 54 had AIDS, and 24 (44.4\%) of the AIDS patients had neurologic manifestations. Of 145 patients whose route of infection was sexual transmission, 110 had AIDS and $83(75.5 \%)$ of the AIDS patients had neurologic manifestations (Table 3). Of 107 patients with neurologic manifestations regardless of route of HIV-1 infection, there were 44 patients (26.8\% of 164 AIDS patients) with central nervous system opportunistic infection, 39 patients $(23.8 \%)$ with HIV dementia, 22 patients (13.4\%) with peripheral neuropathy, 15 patients $(9.1 \%)$ with malignant lymphoma, and 8 patients $(6.7 \%)$ with myelopathy (Table 3 ).

In the second survey, 56 case reports with detailed neurological findings were obtained. Of these 56 patients, 44 had neurologic manifestations (Table 4). Among these 44 patients, there were 12 patients (21.4\%) with HIV dementia, 6 patients $(10.7 \%)$ with central nervous system opportunistic infection, and 5 patients $(8.9 \%)$ with peripheral neuropathy (Table 5). Twenty-nine of the 56 patients died and $21(72.4 \%)$ of the deceased patients had transmission of HIV-1 infection though blood products. The interval between HIV infection and death was 5 years in these 29 patients, and that between onset of neurologic manifestations and death was 7.3 months in these patients who showed such symptoms (Table 6). Of the 29 $(82.8 \%)$ deceased patients, 24 showed neurologic symptoms; disturbance of urination and defecation was observed in 20 patients, gait disturbance in 16 patients, muscle atrophy and weakness in 15 patients, dementia in 12 patients, superficial sensory disturbance in 9 , and ataxia in 8 .
Table 1. Institutions Which Replied to the First Nationwide Survey of Neurologic Manifestations of HIV-1

\begin{tabular}{|c|c|c|}
\hline Institutions & Replied/Contacted & $\%$ \\
\hline University Hospital & $290 / 377$ & 76.9 \\
\hline Internal Medicine & $78 / 98$ & 79.6 \\
\hline Neurology & $28 / 37$ & 75.7 \\
\hline Pediatrics & $76 / 97$ & 78.4 \\
\hline Gynecology & $74 / 87$ & 85.1 \\
\hline \multicolumn{3}{|l|}{ Blood Transfusion } \\
\hline Medicine & $32 / 54$ & 59.3 \\
\hline Others & $2 / 4$ & 50.0 \\
\hline National Hospital & $327 / 482$ & 67.8 \\
\hline Private Hospital & $458 / 816$ & 56.1 \\
\hline Total & $1,075 / 1,675$ & 64.2 \\
\hline
\end{tabular}

Table 2. Neurologic Manifestations Associated with HIV-1 Infection Reported in the First Nationwide Survey

\begin{tabular}{lrc}
\hline \multicolumn{1}{c}{ Diagnosis } & $\begin{array}{c}\text { Number of } \\
\text { Patients }\end{array}$ & $\begin{array}{c}\% \text { to AIDS } \\
\text { patients* }\end{array}$ \\
\hline Patients with HIV-1 infection & 1,854 & \\
Patients with AIDS & 578 & \\
Patients with neurologic manifestations & 166 & 28.7 \\
HIV dementia & 68 & 11.8 \\
Myelopathy & 21 & 3.6 \\
Neuropathy & 15 & 2.6 \\
Malignant lymphoma & 13 & 2.2 \\
Toxoplasma encephalitis & 12 & 2.1 \\
Progressive multifocal leukoencephalopathy & 9 & 1.6 \\
Encephalitis, unknown origin & 7 & 1.2 \\
Cryptococcus neoformans meningitis & 6 & 1.0 \\
Herpes encephalitis & 3 & 0.5 \\
Myositis & 2 & 0.3 \\
Aseptic meningitis & 2 & 0.3 \\
Cerebral infarction & 2 & 0.3 \\
& & \\
One each of & & \\
M. tuberculosis meningitis, Motor neuron disease, Parkinsonism, \\
Neurosyphilis, Cerebral hemorrhage, Amnesia, Mental confusion, \\
Abducens nerve palsy & & \\
& & \\
\end{tabular}

Some of the patients had more than two neurologic manifestations. *The percent is calculated on assumption that these neurologic manifestations were associated with AIDS patients.

\section{Discussion}

In this nationwide survey, epidemiological aspects of neurologic manifestations caused by HIV-1 infection in Japan were clarified. The incidence of neurologic manifestations in patients with AIDS in Japan was $28.7 \%$ and HIV dementia was present in $11.8 \%$ of patients with AIDS. The incidence of 
Table 3. Cumulative Numbers of HIV-1 Carriers, Patients with AIDS and Patients with Neurologic Manifestations of HIV-1 Infection Reported by 34 Institutions in the Second Nationwide Survey

\begin{tabular}{lccc}
\hline All patients & $\begin{array}{c}\text { Patients with } \\
\text { sexual transmission } \\
\text { of HIV-1* }\end{array}$ & $\begin{array}{c}\text { Patients with } \\
\text { HIV-1 infection } \\
\text { through blood products }\end{array}$ \\
\hline Asymptomatic carrier & 148 & 32 & 116 \\
AIDS-related complex & 21 & 3 & 18 \\
AIDS & 164 & 110 & 54 \\
Patients with & $107(65.2 \%)$ & $83(75.5 \%)$ & $24(44.4 \%)$ \\
$\quad$ neurologic manifestations & $44(26.8)$ & $33(30.0)$ & $11(20.4)$ \\
Opportunistic infection & $39(23.8)$ & $28(25.5)$ & $11(20.4)$ \\
HIV dementia & $22(13.4)$ & $18(16.4)$ & $4(7.4)$ \\
Neuropathy & $15(9.1)$ & $14(12.7)$ & $1(1.9)$ \\
Malignant lymphoma & $11(6.7)$ & $7(6.4)$ & $4(7.4)$ \\
Myelopathy & $8(4.9)$ & $7(6.4)$ & $1(1.9)$ \\
Cerebrovascular disease & $2(1.2)$ & $1(0.9)$ & $0(0.0)$ \\
Myositis & $1(0.6)$ & $1(0.9)$ & $2(3.7)$ \\
Parkinsonism & $15(9.1)$ & $13(11.8)$ & $\begin{array}{l}\text { (1) } \\
\text { Other neurologic manifestations }\end{array}$ \\
\hline
\end{tabular}

( ): \% to AIDS patients calculated on assumption that these neurologic manifestations were associated with AIDS patients. *: including patients with unknown route of HIV-1 infection.

Some of the patients had more than two neurologic manifestations.

Table 4. Summary of 56 Patients Reported by 34 Institutions in the Second Nationwide Survey

\begin{tabular}{lc}
\hline Male/Female & $50 / 6$ \\
Age & $37.6 \pm 13.5 \quad$ (range: 10-70) y.o. \\
Stage of HIV-1 infection & \\
$\quad$ Asymptomatic carrier & 3 \\
$\quad$ AIDS-related complex & 3 \\
$\quad$ AIDS & 50 \\
Route of HIV-1 infection: & \\
$\quad$ Blood products & 32 \\
$\quad$ Sexual transmission & 22 \\
$\quad$ Unknown & 2 \\
Neurologic manifestations & \\
$\quad$ present & 44 \\
$\quad$ absent & 11 \\
$\quad$ unknown & 1 \\
\hline
\end{tabular}

neurologic manifestations in patients with AIDS ranged from $26 \%$ to $50 \%$ in other countries $(2,3)$, and HIV dementia was detected in $7.3 \%$ to $15 \%$ of patients with AIDS (3-8). Therefore, the incidence of neurologic manifestations caused by HIV-1 infection in Japan detected in this study was consistent with that in other countries.

The incidence of neurologic manifestations in patients with HIV-1 infection through blood products was lower than that in patients with sexual transmission of HIV-1. This suggests that onset of the neurologic manifestations in patients with HIV-1 infection is modified by factors other than HIV-1 itself. The
Table 5. Neurologic Manifestations in 56 Patients Reported by 34 Institutions in the Second Nationwide Survey

$\begin{array}{lc}\text { HIV dementia } & 12(21.4 \%) \\ \text { Encephalitis/meningitis } & 10(17.9) \\ \text { Toxoplasma } & 3(5.4) \\ \text { Cryptococcus neoformans } & 1(1.8) \\ \text { Cytomegalovirus } & 1(1.8) \\ \text { Herpes virus } & 1(1.8) \\ \text { Unknown } & 4(7.1) \\ \text { Neuropathy } & 7(12.5) \\ \text { Myelopathy } & 7(12.5) \\ \text { Malignant lymphoma } & 2(3.6) \\ & \\ \text { One each of } & \\ \text { Progressive multifocal leukoencephalopathy, Myositis, Cerebral } \\ \text { hemorrhage, Cerebral M. tuberculosis, CNS Aspergillosis, } \\ \text { Diabetes insipidus, Orthostatic hypotension, Cerebellar abscess. }\end{array}$

CNS: central nervous system. Some of the patients had more than two neurologic manifestations.

prognosis of patients with HIV dementia was poor and they died within 4.5 to 7 months on average after onset of this neurologic symptom $(8,14)$. Therefore, complication by neurologic manifestations such as HIV dementia in association with progression of immunodeficiency is one of the most important clinical features influencing prognosis of AIDS patients.

Only $47.2 \%$ of the institutes polled replied to our second survey forms, and thus our results may incorrectly emphasize 
Table 6. Summary of 29 Deceased AIDS Patients Reported from 34 Institutions in the Second Nationwide Survey

\begin{tabular}{lc}
\hline Male/Female & $27 / 2$ \\
Age: & $39.4 \pm 15.0(16-70)$ y.o. \\
Route of HIV-1 infection & 21 \\
$\quad$ Blood products & 7 \\
$\quad$ Sexual transmission & 1 \\
$\quad$ Unknown & 24 \\
Neurologic manifestations & 5 \\
$\quad$ present & \\
$\quad$ absent & $61.3 \pm 41.1(0.5-155)$ months \\
Interval between & $16.1 \pm 13.2(0.5-38)$ months \\
$\quad$ HIV-1 infection and death & \\
$\quad$ onset of AIDS and death & $7.3 \pm 7.3(0.5-30)$ months \\
$\quad$ onset of neurologic manifestations & $\quad 16 / 19(84.2 \%)$ \\
$\quad$ and death & $10 / 11(90.9 \%)$ \\
Abnormal brain CT findings & $0.09 \pm 0.10(0.005-0.45)$ \\
Abnormal brain MRI findings &
\end{tabular}

only some aspects of the clinical features of AIDS patients in Japan. Therefore, it is not possible to draw firm conclusions regarding the epidemiological aspects of neurologic manifestations in Japan solely from the results of this study. More detailed cross-sectional and longitudinal studies will be needed to confirm the epidemiology of neurologic manifestations caused by HIV-1 infection in Japan.

Acknowledgements: We thank the members of the Research Group "Neurologic Manifestations of HIV-1 Infection in Japan" and the participating institutions for their cooperation in these surveys. This work was supported by a research grant from the Japan Health Sciences Foundation.

\section{References}

1) Miyazaki M, Naemura M. Epidemiological characteristics on human immunodeficiency virus infection and acquired immunodeficiency syndrome in Japan. Int J STD AIDS 5: 273, 1994.

2) Lange DJ. AAEM minimonograph \#41: Neuromuscular diseases associated with HIV-1 infection. Muscle Nerve 17: 16, 1994.
3) Trujillo JR, Garcia-Ramos G, Novak IS, Rivera VM, Huerta E, Essex M. Neurologic manifestations of AIDS: a comparative study of two populations from Mexico and the United States. J Acquir Immune Defic Syndr Hum Retrovirol 8: 23, 1995.

4) Janssen RS, Nwanyanwu OC, Selik RM, Stehr-Green JK. Epidemiology of human immunodeficiency virus encephalopathy in the United States. Neurology 42: 1472, 1992.

5) Wang F, So Y, Vittinghoff E, et al. Incidence proportion of and risk factors for AIDS patients diagnosed with HIV dementia, central nervous system toxoplasmosis, and cryptococcal meningitis. J Acquir Immune Defic Syndr Hum Retrovirol 8: 75, 1995.

6) Simpson DM, Tagliati M. Neurologic manifestations of HIV infection. Ann Intern Med 121: 769, 1994.

7) Chiesi A, Vella S, Dally LG, et al. Epidemiology of AIDS dementia complex in Europe. J Acquir Immune Defic Syndr Hum Retrovirol 11: 39, 1996.

8) McArthur JC, Hoover DR, Bacellar H, et al. Dementia in AIDS patients: incidence and risk factors. Neurology 43: 2245, 1993.

9) Kishida S, Young C, Negishi M, Hachimori K, Masuda G, Maeda Y. Seven cases of acquired immunodeficiency syndrome (AIDS) with neurological symptoms. AIDS Journal 1: 247, 1988 (in Japanese).

10) Funata N, Maeda Y, Koike M, Okeda R. Neuropathology of the central nervous system in acquired immune deficiency syndrome (AIDS) in Japan. With special reference to human immunodeficiency virus-induced encephalomyelopathies. Acta Pathol Jpn 41: 206, 1991.

11) Nakasone $T$, Araki $K$, Masuda $M$, et al. A case of acquired immune deficiency syndrome (AIDS) with complicated symptoms. Nippon Rinshou Men'ekigakkai Zasshi (Jpn J Clin Immunol) 14: 216, 1991 (in Japanese with English Abstract).

12) Imai $K$, Tanaka $K$, Shibata $K$, et al. Two cases with acquired immune deficiency syndrome in our hospital. Hokkaido Igaku Zasshi (Hokkaido J Med Sci) 68: 615, 1993 (in Japanese with English Abstract).

13) Ushijima H, Shibuya A. AIDS virus. NO TO HATTATSU 25: 156, 1993 (in Japanese with English Abstract)

14) Arimura $H$, Nakagawa $M$, Maruyama $Y$, Arimura $K$, Osame M. A hemophiliac with human immunodeficiency virus (HIV)-1-associated dementia complex. Internal Medicine 34: 995, 1995.

15) Kawayama T, Murai I, Natori H, Shoji H, Nakashima O. AIDS with progressive multifocal leukoencephalopathy localized at the brainstem and cerebellum. A case report. Neurol Med 42: 360, 1995 (in Japanese).

16) 1993 revised classification system for HIV infection and expanded surveillance case definition for AIDS among adolescents and adults. MMWR 41: 1, 1992.

17) Ministry of Health and Welfare. Guideline for AIDS case definition, 1983 (in Japanese). 